\title{
Identidades del caribe insular colombiano: otra mirada del caso isleño-raizal
}

\author{
Inge Helena Valencia
}

\begin{abstract}
In the Constitution of 1991, Colombia is defined as an ethnically plural and multicultural nation. This has implied the recognition of special rights and statutes of different populations and their territories, including, amongst others, the native population of the San Andrés, Providencia and Santa Catalina Islands. This recognition has caused the re-elaboration and reinvention of identity discourses by the native population. At the same time it has fostered conflicts between some sectors of this population and the Colombian State. This essay analyzes the discourses and other elements in the self-representation of the population, which construct the native identity, in order to explore the values that form that identity in the inter-cultural daily life of the Caribbean region.
\end{abstract}

En el marco de las políticas del reconocimiento, la Constitución Política de 1991 reconoce a las poblaciones indígenas, negras, gitanas y raizales como expresiones de la diversidad de la nación. Estas transformaciones institucionales y jurídicas, que han estado orientadas a dar viabilidad a un proyecto de nación incluyente, son el resultado de diversas y complejas articulaciones entre dinámicas locales y globales. El reconocimiento de la diversidad étnica y cultural, así como la reivindicación de ciertos derechos diferenciales, pusieron sobre la mesa el problema del desequilibrio estructural de las relaciones sociales y culturales entre diversos sectores y grupos de la sociedad colombiana.

Para el caso de la población isleña-raizal del Archipiélago de San Andrés, Providencia y Santa Catalina este reconocimiento en el escenario político colombiano ha tenido varias implicaciones. Primero, incentivó a la población isleña-raizal a configurarse y posicionarse como sujeto étnico y político, a través de la formalización de ciertos canales de participación política, que se materializan a su vez en la existencia de diversos tipos de organizaciones que se adjudican la defensa de los derechos de esta población. También esta situación implicó una reelaboración en la manera como la población isleña-raizal ha 
asumido la particularidad de su identidad, las maneras de pensarse, reinventarse y a la vez proyectar su diferencia a través de relaciones establecidas con otras poblaciones y con el Estado colombiano. La población isleña-raizal, si bien hoy es reconocida como minoría étnica, ha vivido un largo proceso para adquirir este reconocimiento y a la vez ciertos derechos particulares. Actualmente la relación establecida entre el Estado colombiano y algunos pobladores parece agravarse por la compleja situación política y social que se vive en el Archipiélago y que ha generado expresiones políticas cada vez más radicales de sus habitantes, al punto de que un sector se resiste a identificarse como colombiano

Esta relación conflictiva se ha producido principalmente por la manera como el Estado colombiano ha pretendido integrar al Archipiélago a su proyecto nacional. Integración que se transforma y que se percibe a partir de la manera como el Estado ha concebido a sus pobladores: de población nativa que debía ser integrada y asimilada a un único proyecto de nación -a través de la modernización e hispanización- al actual reconocimiento, al menos en "ley", como minoría étnica poseedora de ciertos derechos y protegida según los designios constitucionales. De todas maneras, estas dos formas de concebir la "colombianidad" de los isleños tienen un común denominador: el conflicto generado por la integración, sea ésta impuesta, como lo fue desde la Constitución de 1886, o negociada como aparentemente lo ha sido desde 1991. Después de casi cien años en que se buscó la integración de la población isleña a través de la asimilación y, por qué no, del menosprecio de su identidad y de sus costumbres -como sucedió con el créole y la religión bautista- actualmente se pide a los isleños que propendan por la protección y defensa de su propia identidad. Entonces, vale la pena preguntarse: ¿Qué elementos construyen la identidad isleña más allá de los que podemos definir como manifestaciones culturales propias de esta población? ¿Cuáles son esos elementos a recuperar, mantener y proteger? Y, sobretodo, de esa identidad propia, raizal, isleña, ¿cuáles son los dispositivos identitarios que han permitido un estado de convivencia entre diferentes grupos sociales en un lugar tan pequeño como el Archipiélago?

Frente a los impactos del reconocimiento constitucional, vale la pena hacer algunas aclaraciones que pueden ser tomadas como marco de referencia para las reflexiones que se presentan a continuación. A la vez que el reconocimiento produce una "explosión" de organizaciones y movimientos sociales que luchan por la defensa de la identidad y derechos de las poblaciones reconocidas, también se genera una fuerte producción discursiva con relación a la reafirmación y producción de identidades de corte étnico, sustentada en la búsqueda de muchas poblaciones por acceder a los derechos y ventajas que ofrece el reconocimiento constitucional. Como lo plantea Ingrid Bolívar (1998) “el marco normativo 
otorgado por la Constitución, ha generado que durante estas últimas décadas haya grupos humanos que se estén construyendo o reinventando como diferentes". Aquí podríamos citar varios casos, como el de la población kuankuama de la Sierra Nevada de Santa Marta (Morales, 2000), los muiscas en Bogotá, o para el caso que nos compete, la población isleña-raizal del Archipiélago de San Andrés, Providencia y Santa Catalina.

Además del impacto en las poblaciones, también vale la pena hacer referencia a cómo esta lógica de la etnización impactó sobre los estudios que se comenzaron a generar. Después de la década de 1990 asistimos a una proliferación de aproximaciones sobre las minorías, sus dinámicas y problemáticas, que tuvieron como enfoque de análisis el fenómeno de la etnicidad, entendida esta en líneas generales como la instrumentalización estratégica de la identidad. De la misma manera, muchos de estos estudios privilegiaron las perspectivas de análisis a partir de la relación establecida con el Estado y la sociedad nacional. Para Anne Marie Losonczy (2002) la lógica de la etnización y los estudios que se derivaron de ella, a pesar de ampliar el panorama con relación a grupos históricamente excluidos, produjo también una especie de sesgo. Para Losonczy este tipo de análisis privilegió la manera de aproximarse a las poblaciones reconocidas, a través de la reafirmación de una fuerte dicotomía establecida en la relación entre las poblaciones definidas como "comunidades étnicas" y la sociedad nacional. Estos análisis a su vez produjeron una visión excesivamente homogenizadora, que pretende leer las particularidades de estas poblaciones a través de los procesos de articulación a las sociedades nacionales blancas-mestizas desde los registros de la marginalidad, los procesos de confrontación y resistencia, o el reconocimiento desde las acciones realizadas a partir del campo de la política formal. Así, otros campos de estudio u otras perspectivas de análisis, como los estudios de las relaciones interétnicas e interculturales, no han tenido la misma pertinencia y atención.

Esta reflexión busca analizar los discursos y elementos que se reivindican al abordar los procesos de construcción de la identidad isleña-raizal, para entender cómo esta también es construida a partir de valores sociales o representaciones propias de la población. Lo importante aquí no radica en realizar una tipificación de esta población y reafirmar que posee su lengua (el créole), ${ }^{1}$ su territorio (el

El origen de esta lengua es lo que Okley Forbes denomina un pidgin, es decir, una variante lingüística o lengua vehicular creada con el propósito de servir de instrumento de comunicación entre dos grupos humanos o comunidades lingüísticas diferentes. Así, un pidgin se origina a partir de otra lengua, reduciendo sus estructuras sintácticamente y las variaciones morfológicas. Para el caso del Archipiélago, de acuerdo con su historia colonial, el 'creole' que se habla es el resultado del encuentro entre el inglés de los primeros colonizadores ingleses y las adaptaciones que a éste le hacen los esclavos africanos provenientes de Jamaica para poderse comunicar (Forbes 2002: 124). 
Archipiélago) y su cultura propia. Lo que nos interesa comprender es cuáles pueden ser otros valores sociales que construyen la identidad isleña-raizal y que permiten a ciertas personas reconocerse e identificarse con ella. Es decir, pretendemos conocer qué elementos actualmente constituyen la identidad isleñaraizal, o en palabras de E. Cunin (2000): “conocer los vectores de valorización de la identidad, los modos de identificación, para llegar a descifrar cuáles son los símbolos identitarios que fundan la creencia del origen común" y que son los que finalmente han permitido la configuración de una identidad isleña-raizal en medio de la convivencia con otros grupos sociales en un pequeño territorio que pertenece a la región Caribe.

\section{Región Archipiélago}

El archipiélago de San Andrés, Providencia y Santa Catalina ha sido conocido por el conflicto territorial de aguas marítimas con Nicaragua y por las famosas y pretendidas intenciones separatistas de un sector de la población. También porque el Archipiélago se ha constituido como destino turístico por excelencia, y actualmente porque sus pobladores deben hacer frente a una crisis socioeconómica y ambiental por el fracaso de la imposición de un modelo de desarrollo que acarrea múltiples cuestionamientos e interrogantes sobre su futuro.

Es importante mencionar que las condiciones particulares de las islas -como su composición étnica y cultural, y su desarrollo económico- han generado siempre grandes desacuerdos frente al proyecto de nación colombiana. Debido a su temprano poblamiento, realizado de una manera muy distinta a la de Colombia continental, su configuración ha estado signada por dinámicas bastante particulares, entre ellas el hecho de estar inscrito en la región Caribe y obedecer a muchas de sus características. Las islas de San Andrés y Providencia fueron pobladas mediante los ciclos migratorios provenientes de las colonizaciones inglesa y española. De ser uno de los primeros asentamientos de los puritanos -calvinistas que venían directamente de Inglaterra-, las islas fueron abandonas por un tiempo, para después ser repobladas por jamaiquinos, descendientes directos de la diáspora africana (esclavos) y otros pobladores que migraban entre distintas islas y territorios del Caribe Occidental. Estas migraciones, con sus respectivas particularidades culturales, económicas y sociales, han dado como resultado que la población originaria de las islas, la población “isleña-raizal, sea anglófona y en su mayoría protestante. También es importante precisar que en el Archipiélago habitan personas de diversos orígenes que han llegado de Colombia, de otros lugares de Centro América -Nicaragua, Colón en Panamá o Puerto Limón en Costa Rica- y de otros países como Italia, España, Líbano y Siria. 
Debido a estas diferencias, la relación establecida entre los pobladores del Archipiélago y el Estado colombiano ha estado caracterizada por un matiz conflictivo que nace por la manera como este pretendió integrar al Archipiélago a su proyecto nacional. A pesar de que son los isleños quiénes deciden adherirse a los Estados Unidos de Colombia en el año 1823 (Parsons, 1985), es desde la segunda década del siglo XX que el Estado colombiano busca integrar al Archipiélago a través de un fuerte proceso de asimilación. Para ello se impusó a sus habitantes la religión católica, se prohibió el inglés como lengua en las escuelas, e incluso se llegó a clausurar a mediados del siglo varias iglesias bautistas, que se constituían como el eje socio-cultural y educativo del Archipiélago. ${ }^{2}$ Tal situación se vio recrudecida con los cambios producidos con la declaratoria de San Andrés Isla como puerto libre en el año 1953, y posteriormente con el desarrollo del turismo como principal actividad económica. A partir de este momento se originaron grandes desequilibrios económicos y ambientales, y a su vez se generó un fuerte conflicto intercultural como consecuencia del abrupto cambio demográfico y territorial generado con la declaratoria. De la misma manera las grandes transformaciones acaecidas con este proceso de integración, tuvieron impacto en otros campos, como aquellos relacionados con la educación y la lengua. Lo cierto es que este proceso de integración o "colombianizacion" para establecer soberanía a través de medidas de carácter ideológico y de integración económica, vía modernización y desarrollo, recrudecieron los conflictos en el Archipiélago y fortalecieron su confrontación frente al Estado colombiano.

La transformación cultural de la población isleña-raizal, alcanzada en el marco de los cambios políticos y económicos, deja en claro que los efectos tanto internos como externos de los desarrollos a nivel global, regional y local sobre la cultura de una sociedad son decisivos. En este sentido "la cultura se muestra como un proceso que no puede ser detenido y que sigue desarrollándose en las más diversas circunstancias e influencias" (Ratter, 1991: 135). En San Andrés, tras 50 años de fuertes cambios y transformaciones socioeconómicas, las fronteras entre los diferentes grupos sociales que lo habitan se han vuelto muy difusas y a la vez el sentido de diferencia se ha recrudecido. Esto ha permeado la manera en que los diferentes grupos se ven a sí mismos y como establecen relaciones entre

\footnotetext{
2 Desde el año de 1926 hasta 1975 la misión católica tuvo la responsabilidad de la educación en las islas. Durante todos estos años el discurso escolar estuvo entreverado con lo católico, por lo tanto se adelantó notablemente el proceso de nacionalización, dándose importantes pasos al impartir varios conceptos morales y sociales de la nación colombiana. La conversión a la fe católica llegó a ser requisito para ocupar cargos públicos y disfrutar de otros beneficios oficiales como el de recibir becas universitarias. Se llegó inclusive a cerrar colegios donde todavía estudiaban la gran mayoría de niños y jóvenes. En el año de 1943 se impone el español como lengua oficial del Archipiélago, prohibiendo el uso del inglés en los colegios y en los documentos públicos (Vollmer, 1997: 65).
} 
sí, agregando a este panorama un nuevo conflicto: la ruptura de la convivencia entre la población isleña-raizal y la de origen continental.

\section{¿Raizales Afros?}

Es importante señalar que respecto a la definición de la población isleña-raizal vale la pena reflexionar sobre su condición "afro". Como lo plantea Eduardo Restrepo (2005: 35), las representaciones académicas de lo negro en Colombia han sido estructuradas teniendo a la región pacífico como paradigma. Aunque demográficamente los afrodescendientes se encuentran localizados en contextos urbanos -en ciudades del Pacífico como Quibdó, Buenaventura y Tumaco; del interior del país como Cali, Bogota y Medellín; o de la costa Caribe como Cartagena o Barranquilla-, son relativamente escasos los estudios que exploran las dinámicas culturales e históricas de estas poblaciones desde una perspectiva comparativa.

Además mientras el grueso de los trabajos se refiere a las áreas rurales, mucho más escasos son los estudios que se han centrado en comprender las dinámicas histórico-culturales de las poblaciones negras urbanas del país. Como consecuencia, desde una perspectiva de análisis espacial, además de la pacificalización ya anotada, se puede plantear una ruralización en la producción académica del negro en Colombia. (Restrepo, 2005: 139).

Para el caso particular de la población isleña-raizal surgen preguntas relacionadas con su condición caribe, que en esta topología espacial no obedecería ni a un contexto completamente urbano ni a un contexto completamente rural. Además, se ha generado un conflicto relacionado con el estatus limitado que se ha asociado a la cultura negra con aquella propia de la región del Pacífico colombiano, establecida en la ley 70 de 1993 o ley de comunidades negras, ${ }^{3}$ ya que esta homogeniza a los "afros" de diferentes regiones (Pacífico, Costa Atlántica, Antioquia, Cauca, Nariño, etc.) con los "raizales” del Archipiélago, desconociendo así la historia propia de las islas y las necesidades particulares de sus habitantes producto de la condición insular (Avella, 2000).

Este hecho también ha ocasionado que sectores de la población busquen legitimar sus derechos a partir de la recreación de identidades de corte étnico, lo cual ha tenido varias consecuencias. Entre ellas se destaca la diversidad de posturas con relación a la definición del ser raizal -esto puede ser visto en la utilización de denominaciones

\footnotetext{
3 "Comunidad negra ha sido definida como el conjunto de familias de ascendencia afrocolombiana que poseen una cultura propia, comparten una historia y tienen sus propias tradiciones y costumbres dentro de la relación campo-poblado que revelan y conservan conciencia de identidad que las distingue de otros grupos étnicos" (ley 70 de 1993, artículo 2, parágrafo 5).
} 
como pueblo indígena raizal, etnia anglo-afro-caribeña o comunidad raizal-, y una gran discusión con relación a los elementos y prácticas que la constituyen (Valencia, 2002). Para el caso de la reivindicación de la condición afro, esta proviene de una élite que ha estado familiarizándose con los procesos de las comunidades negras y que gracias a esto mismo conoce los beneficios sociales, políticos y económicos que ha traído afirmarse como "negros" y, por tanto, hoy lucha por la aceptación del término y el rescate de la herencia africana (Rivera, 2002: 68).

De igual manera, vamos a encontrar una diferencia en la manera en que estos discursos identitarios son utilizados, generalmente en la interlocución con el Estado o con otras instituciones -ONG's, agencias de cooperación- y la manera como la población isleña-raizal se reconoce a sí misma en la cotidianidad. Esta situación puede ser vista en la diferencia que existe al denominarse como "isleño", denominación que utiliza la mayoría de la población cotidianamente, y denominarse como "raizal", denominación que posee un fuerte matiz político, una intención reivindicativa, y que es utilizada primordialmente en los espacios académicos y políticos. Que hoy exista una gran pregunta por la condición de la población isleña-raizal, por los elementos que hacen parte de su identidad, nos lleva a la necesidad de rastrear la manera en que sus discursos identitarios han sido construidos, desde los legados de la experiencia colonial hasta aquellos creados como respuesta al reconocimiento producido por la Constitución de 1991.

\section{Los discursos de la reconfiguración étnica: la invención de una etnia afro-anglo-caribeña}

De acuerdo con las reconstrucciones históricas que se han hecho del Archipiélago (Wilson, 2005; Parsons, 1985), es a partir de la llegada de Francis Archbold a fines del siglo XVIII cuando se empieza a gestar el más "reciente" asentamiento permanente y estable de las islas. Este se realiza bajo la estructura de plantación esclavista que, dada su permanencia y el incremento poblacional que genera, asienta las bases de la actual sociedad isleña y con esto una estructura social con una serie de características específicas fundamentadas en las diferencias dadas por clase y color. Uno de los trabajos mas importantes sobre etnología caribe realizados en esta región -concretamente en la isla de Providencia- fue el realizado por Peter Wilson. Este antropólogo sugirió que para comprender la organización de la vida social en las sociedades caribes era necesario entender la relación entre raza y clase a través de una estructura social, manifiesta en dos sistemas de creencias o valores significantes denominados como "reputación" y "respetabilidad". Estos valores resultantes de las relaciones de dependencia establecidas en el contexto colonial se contraponen en la estructura de la sociedad, 
trascendiéndola. Para Wilson estos valores son estructurantes de la sociedad isleña y expresan cómo la gente se divide en términos de sus relaciones sociales y productivas.

Para Wilson, la respetabilidad es el eje de la jerarquía en un mundo originalmente diseñado por otros, por los europeos poseedores del poder. Un sistema de clases estratificado que define el acceso a la respetabilidad, donde lo que otorga la respetabilidad es la posición socioeconómica que Wilson denomina como "high class". La reputación es una respuesta a la dependencia colonial y a lo elusiva que es la respetabilidad. Esta es un factor de nivelación de alguna clase de recompensa por la escasez de respetabilidad y favorece la igualdad en sistemas en los que la igualdad socioeconómica para la mayoría es inalcanzable, determinando otra clase "the others" (Mintz en Wilson, 2003: 19).

Para Wilson la "high class" reproduce aquellos valores provenientes de la clase dominante en el contexto colonial. Esta se asocia con la riqueza en términos económicos y en relación con la posesión de grandes extensiones de tierra; el color, en tanto más claro, y sobretodo por poseer un estilo de vida "respetable", refiriéndose al conjunto de valores que estructuran a la clase social alta, es decir, una "buena educación", una fervorosa vida religiosa, unas "buenas maneras", un inglés "apropiadamente hablado" y una determinada "sensibilidad moral y ética" aconsejada por esta misma institución. De otro lado, "the others" reproducen aquellos valores asociados a la descendencia africana, la ocupación en los sectores económicos menos reconocidos, en las actividades tradicionales como la pesca y agricultura y los valores otorgados por la "reputación", que hace referencia a la constelación de valores que estructuran este grupo social y que se define como la expresión propia de la respetabilidad (Rivera 2002, tomado de Wilson).

En estos términos la reputación y la respetabilidad están al mismo tiempo contrapuestas y entrelazadas a los principios del comportamiento social. Wilson, a través del caso de Providencia, argumenta que las experiencias históricas de las tierras caribes han dado origen a una dialéctica social en la cual todos los valores están regularmente opuestos el uno al otro (Mintz en Wilson, 2003: 20). Para Wilson la respetabilidad tiene sus raíces en la sociedad colonizante externa, aunque en una instancia dada su realidad depende del rol integral de la sociedad en el sistema social de la colonia. La reputación, de otro lado, es "indígena" a la colonia y es en ambos un principio estructural auténtico (Avella, 2000).

La importancia en resaltar los valores de la reputación y la respetabilidad radica en reflexionar cómo estos han permeado las propias representaciones que la población isleña-raizal ha construido de sí misma. Vamos a encontrar que estos, además de reforzar ciertas diferencias socioeconómicas y raciales, tienen una directa 
incidencia en la manera en que la población piensa y construye sus discursos sobre la identidad. Además, como lo plantea Camila Rivera (2002), este esquema sociocultural sigue estando vigente a pesar de las transformaciones que se han vivido en las islas a partir del constante contacto con otras sociedades, incluyendo la colombiana. De hecho, podría decirse que estas estructuras sociales, que se vienen forjando desde la colonización inglesa, son reforzadas con la entrada y permanencia de casi un siglo en las islas del discurso hegemónico y homogenizador de nación propuesto por el Estado en la Constitución de 1886:

En el proyecto regenerador que acompañó esta Constitución se proponía una orientación muy similar al esquema que venia estructurando las islas: el blanqueamiento cultural y físico visto como una virtud, como la mejor manera de ascender en prestigio de acuerdo a la jerarquía nacional, y lo negro como un defecto moral, un sustrato inferior que debía desaparecer (Rivera, 2002: 102).

Este tipo de valores, además de incidir en la manera en que la gente construye sus propias representaciones, incide en el tipo de elementos que son rescatados y reivindicados para darle forma a esa identidad que se reinventa a partir del reconocimiento otorgado por la Constitución Política de 1991. Si bien existe una relación entre la respetabilidad y ciertos rasgos provenientes de la herencia inglesa, y la reputación se encuentra asociada a ciertos valores provenientes de la descendencia africana, actualmente encontraremos que tanto elementos de la herencia inglesa como africana son retomados y reivindicados para darle forma a la identidad isleña-raizal. No en vano actualmente la población isleña-raizal se define así misma como etnia anglo-afro-caribeña.

Aquí se evidencia ese carácter problemático con relación a la identidad, a cómo fijar o moldear algo que se está transformando, o qué elementos elegir a la hora de definir una identidad. Tal vez el caso de la población isleña-raizal sea uno de los más ilustrativos en aras de entender lo disímiles que pueden ser los discursos que reivindican una misma identidad, o lo difícil que resulta crear o reinventar los elementos que conforman este tipo de procesos. Por ejemplo, para el caso isleño-raizal la superposición de las herencias inglesa y africana ha tenido como resultado que la población isleña busque la conciliación a través de un solo discurso, definiéndose a sí misma como etnia afro-anglo-caribeña, pueblo indígena raizal o comunidad raizal en respuesta a la exigencia de una única identidad establecida por la Constitución de 1991. Es importante mencionar que el tratar de conciliar estos discursos no ha dejado de ser problemático y no todos los sectores de la población isleña comparten los discursos y prácticas que implican este tipo de denominaciones. El reivindicar estos orígenes -tan disímiles entre sí- deja entrever dos problemas: por un lado, lo difícil que resulta 
para la población isleña-raizal intentar construir una identidad imaginada de corte étnico, pues esto implica resaltar una ancestralidad que precisamente no poseen por su particularidad histórica de múltiples orígenes propia de su condición "caribe". Y segundo, "la población isleña-raizal se ve enfrentada a conflictos generados en el intento por ponerse de acuerdo en cuanto a la aceptación de su procedencia, es decir, en la reafirmación de una descendencia "africana" o de una descendencia "inglesa"” (Rivera, 2002).

Como resultado de lo anterior, la respuesta ante la necesidad de construcción de una única identidad ha sido reafirmar la propia identidad a partir de la diferencia con otros. Si la identidad isleña-raizal ha tenido tantas dificultades para lograr su consolidación debido a su herencia colonial, a los debates entre la herencia inglesa o africana, a las memorias y elementos que se rescatan, el mejor mecanismo ha consistido en construirse en oposición a un tercero, ese "otro" que no comparte la mayoría de sus valores tradicionales: el continental o "paña", proveniente en su mayoría de Colombia continental. Además, ese interés por diferenciarse de los colombianos continentales encuentra cabida debido a los procesos adelantados en la Constitución de 1991 en aras del reconocimiento y respeto a la diferencia étnica y cultural:

Uno de los problemas que tenemos es que nos falta un nombre adecuado para designarnos. Primero nos decíamos “isleños” pero cuando empezó a llegar gente de otras partes a la isla comenzamos a darnos cuenta que ellos también adoptaron ese nombre. Nos llamamos entonces "nativos", pero las personas que llegaron tuvieron hijos que nacieron aquí y éstos también dicen que son nativos. Por eso, desde los años ochenta se empezó a usar el término raizal para referirse a nuestro grupo étnico. Pero ese apelativo tampoco parece adecuado. Queremos, pues, un nombre propio como lo tienen las naciones indígenas de Colombia (Juvencio Gallardo, citado en Ramírez, 2001). ${ }^{4}$

La búsqueda de definición con respecto a la de identidad de la población raizal permite percibir algunos problemas de una multiculturalidad sin sujeto diferenciable en términos culturales, pero sí étnicos de acuerdo al discurso oficial, pues tanto la mayoría de los continentales o pañas, como los isleñosraizales, se podría decir pertenecen al mismo complejo afrocaribe (Avella, 2002a: 23). Lo problemático es que al existir una identidad étnica reconocida

\footnotetext{
${ }^{4}$ Bajo el título "El grito de una etnia despojada" el padre Giraldo (1987) publica en la revista Controversia del Cinep el manifiesto del Movimiento Sons of the Soil, donde se hacen las denuncias frente a los daños causados por el modelo de desarrollo impuesto desde el Puerto Libre. En este artículo se acuña por primera vez el término de “raizales" para denominar a la población originaria del Archipiélago de San Andrés, Providencia y Santa Catalina. Desde este momento el término "raizal" será utilizado por los miembros de las diferentes organizaciones étnicas y sociales de San Andrés para denominar a quienes consideran es el pueblo nativo de las islas.
} 
por la Constitución de 1991, al establecer límites en quiénes son reconocidos y quiénes no, y quiénes se benefician del reconocimiento de ciertos derechos, se ha generado un profundo conflicto en el Archipiélago. En este caso, desde la población isleña-raizal se ha permitido denominar al mismo grupo afrocaribe como "el otro", el paña y ahora invasor.

Finalmente vale la pena aclarar que a partir de la manera como se ha apropiado el discurso de lo étnico, como elemento constitutivo de la identidad, existe una diferencia entre estos discursos identitarios creados hacia afuera y la manera como la gente isleña-raizal se reconoce a sí misma en la cotidianidad. Porque lo que ha sucedido es que en la puesta en escena de estos discursos hacia fuera existe hoy una especie de olvido hacia otro tipo de valores que también construyen la identidad. Hoy se olvidan esos otros mecanismos de identificación, construidos desde las prácticas culturales, de lo cotidiano y lo popular, que paradójicamente son los mecanismos que realmente han logrado mantener el estado de convivencia intercultural, que históricamente ha caracterizado al Archipiélago.

\section{Otras miradas: identidad, migración e interculturalidad}

En esta rápida aproximación a la cuestión identitaria de la población isleña raizal se evidencian ciertos marcadores étnicos propios de la identidad como la lengua, la cultura y el territorio propios (Barth, 1976). ${ }^{5}$ También percibimos la existencia de un rescate de las manifestaciones culturales o de las herencias y memorias como elementos constitutivos de la identidad (Bolívar, 1997). Pero si las identidades son construcciones históricas, plurales, que nunca dejan de transformarse, vale la pena preguntarse por la existencia de otro tipo de miradas que permitan aprehender su carácter dinámico. Y no sólo en tanto lo que significa comprender los procesos de transformación que hoy viven las sociedades caribes y su relación con la identidad, sino en lo que significa pensar estos procesos en contextos eminentemente interculturales. Para ello Anne Marie Losonczy

\footnotetext{
${ }^{5}$ Anticipándose, o quizás avizorando las consecuencias de procesos relacionados a la diversidad social y cultural, Fredrik Barth propuso la definición de "grupo étnico". Uno de los aspectos más relevantes de las propuestas de Barth es el hecho de que sus conceptos se utilizaron, sobre todo, para describir la incorporación de grupos minoritarios en sociedades más amplias. De acuerdo con este autor, los grupos étnicos son formas de organización social socialmente efectivas, debido a que funcionan como "categorías de adscripción e identificación que son utilizadas por los actores mismos y que tienen, por tanto, la característica de organizar la interacción entre los individuos" (1976: 10). Partiendo de este planteamiento Barth señala que: "El término grupo étnico es utilizado generalmente en la literatura antropológica para designar una comunidad que: i) en gran medida se auto perpetúa biológicamente; ii) comparte valores culturales fundamentales realizados con unidad manifiesta en formas culturales; iii) integra un campo de comunicación e interacción; iv) cuenta con unos miembros que se identifican a sí mismos y son identificados por otros y que constituyen una categoría distinguible de otras categorías del mismo orden".
} 
(2006) nos invita a reflexionar sobre la importancia de elaborar una mirada a la cuestión identitaria desde una aproximación interétnica:

El término interétnico no apunta solamente a la exploración de la interrelación sistemática que puede ser constructora de lo propio entre grupos culturales que representan su particularidad con un marcador discursivo de tipo étnico. Puede incluir igualmente el análisis de los intersticios e intersecciones culturales entre colectivos que no se definen ni a ellos mismos ni a los otros en términos étnicos. Una perspectiva interétnica pretende integrar, en este horizonte analítico de inspiración culturalista, los armazones y competencias sociales y políticas internas y autónomas de estos grupos que al tejer continuos intercambios con otros cercanos construyen sociabilidades interdependientes, anclajes sociológicos de la hibridación cultural (Losonczy, 2006: 17).

¿Cuáles son esos mecanismos que permiten comprender los procesos de construcción de identidad desde una mirada interétnica? ¿Cuáles pueden ser las competencias sociales y políticas internas y autónomas? ¿Cómo puede establecerse una mirada interétnica sobre los procesos de construcción de identidad de la población isleña-raizal? Para Losonczy existen varios elementos que pueden ser útiles para develar estos procesos. Primero, el comprender la existencia de relaciones entre grupos que no necesariamente se definen -o se definían- a partir de una frontera étnica cerrada; y segundo, la existencia de una competencia a la movilidad o migración y su impacto sobre los procesos de socialización. Retomando estas ideas, para el caso de la población isleña el compartir la realidad insular del Archipiélago, sustentado en un pasado común marcado por sucesivas oleadas migracionales y la existencia de relaciones propias del contexto intercultural de éste, hace que existan ciertos elementos que definen la identidad isleña-raizal desde esta mirada interétnica. Por ejemplo, la tradición de la migración históricamente ha sido uno de los determinantes de las sociedades caribes, que actualmente es acuñado como diáspora. El utilizar el término de diáspora, para aproximarse a las distintas migraciones que han existido en el Caribe, significa "hacer referencia al movimiento, sea voluntario o forzado de un grupo, una comunidad o una etnia, que se produce en la búsqueda de un nuevo territorio para asentarse y llevar a cabo actividades de distinta índole" (Avella, 2002: 2). La importancia de entender la conformación del Caribe a través de las diásporas radica en que estas significan la conformación de la región en tanto movimientos migracionales, pero también en la medida en que estas producen los fenómenos de intercambio cultural y creolización que permiten conformar los rasgos culturales propios de las poblaciones de este territorio. 
En el Caribe es importante mencionar que la noción de diáspora ha hecho referencia principalmente al transplante obligado de población africana establecida por la trata trasatlántica, donde el trabajo de Paul Gilroy, Black Antlantic (1993), se constituye en uno de los más importantes aportes para entender la conformación de las sociedades caribeñas a partir de la diáspora africana y de las condiciones establecidas por esta:

Sea cual sea la diversidad de términos utilizados, "diáspora negra", "diáspora africana", "diáspora afro-antillana", "diáspora híbrida", "black atlantic", (...) las poblaciones que se trata de designar presentan una unidad ligada a un orígen idéntico: la trata (de esclavos) tras-atlántica. La diáspora en cuestión es aquella formada por los descendientes de millones de africanos deportados a las Américas a partir del siglo XVI, desde la captura violenta y la sumisión de los africanos a las condiciones inhumanas ordenadas por el sólo imperativo del enriquecimiento económico (Gilroy, en Chivallon 2004: 45). ${ }^{6}$

Aun así, a pesar del enorme significado e impacto que ha tenido la diáspora africana en la conformación de la sociedades e identidades propias del Caribe, es importante mencionar que en esta región han confluido otras migraciones provenientes de diferentes orígenes: inglés, francés, holandés, chino, indio, sirio, libanés, ocasionando que las poblaciones originarias de estos territorios fueran suplantadas por estas olas migracionales de muy diversa filiación cultural, lingüística y étnica:

Como consecuencia de este complejo cuadro de implantaciones coloniales y de articulaciones étnicas, sociales y culturales, además de diversas herencias políticas y distintas formas de articulación económica, se originaron nuevas relaciones que junto con más de cuatro siglos de presencia colonial, dejaron una gran huella cultural que ha marcado tanto las combinaciones etnoraciales que caracterizan a las poblaciones locales, como las modalidades lingüísticas y culturales que las hacen distintivas (Serbín, 1987: 75).

Las diásporas o movimientos migracionales han incidido profundamente en la configuración identitaria de las poblaciones caribes debido a los constantes intercambios y contactos, porque con los movimientos, no es sólo la población la que se desplaza sino también la cultura la que se transforma y afianza. El encuentro de estas migraciones, al actuar como flujos de relaciones sociales,

\footnotetext{
${ }^{6}$ Quelle que soit la diversité des termes utilisés, "diaspora noire", "diaspora africaine", "diaspora afro-antillaise", "diaspora bybride", "black antlantic", "diaspora bybride" (...) les populations qu'il s'agit de désigner offrent une unité liée à une origine identique: la traite transatlantique. La diaspora en question est celle formée par les descendants des millions d'Africains déportés aux Amériques a partir du XV Te siecle, depuis l'arrachement violent et la soumission des africaines a des conditions inhumaines commandées par le seul impératif de l'enrichissement économique (Gilroy, en Chivallon 2004: 45). (Traducción del editor)
} 
produce nuevas identidades, dando como resultado la superposición y sincretismo tanto cultural como político y económico que caracterizan al ámbito Caribe.

Es importante mencionar que la conformación de las identidades en el Caribe a través de comunidades de diversos orígenes ha hecho que este lugar se establezca como una región eminentemente intercultural. Desde esta perspectiva, lo que pretendemos ejemplificar es cómo el encuentro de migraciones determina la construcción de identidades con base en las confrontaciones culturales o en los procesos de creolización, entendidos como esa capacidad para apropiar y resignificar elementos externos para volverlos propios. De esta manera, la construcción de identidad de la población isleña-raizal puede enmarcarse en los procesos de configuración de las identidades en el Caribe. Las identidades del Caribe son, como lo diría Hall, las identidades de la diáspora. No la diáspora esencial y pura "de esas tribus esparcidas cuya identidad sólo se puede afianzar con relación a una patria sagrada", sino más bien la diáspora en términos de la heterogeneidad, la diferencia y la forma particular de hibridación, dada principalmente por la presencia europea, africana y americana, donde las diversas identidades afrocaribeñas se construyen "a partir de una dinámica sincrética que se apropia, de manera crítica, de elementos provenientes de códigos maestros de la cultura dominante y los "creoliza" desarticulando los signos presentes, y re-articulando su significado simbólico" (Hall en Rivera, 2002). Esa forma particular de apropiación, la creolización, es lo que constituye la especificidad y a la vez la paradoja de la identidad caribe: "tratar de representar un pueblo diverso con una historia diversa, a través de una identidad "única" y hegemónica" (Hall en Rivera, 2002). Esta definición de la identidad caribe no se limita a una aproximación estática de lo sincrético. Por el contrario, a través de estos intercambios, provenientes del encuentro de las identidades de la diáspora, las poblaciones caribes han guardado una especie de patrón multicultural definido por la idea de pertenecer por "origen" a diversas culturas que ya no se pueden reducir ni al color de su piel ni a sus comportamientos particulares, pero que han quedado grabados en una sola memoria: la de su pertenencia a un territorio y a una identidad caribe. De aquí pueden rescatarse dos cosas. La primera es la conformación de identidades a partir de orígenes diversos pero que en su diversidad afirman la pertenencia a un origen común:

Para nosotros el Caribe es, como decimos en latín, "Unitas Multiplex", y la identidad común caribeña no puede ser otra que una identidad compleja. Esta es la razón por la cual no deberíamos privilegiar y amplificar lo uno y devaluar o reducir lo diverso, para encontrar y comprender la identidad común Caribeña. Tenemos que asociar lo común y lo diverso, lo parecido y lo diferente -ambos constitutivos de la combinación que es la identidad 
común Caribeña- y es este elemento de combinación lo que importa (Manigat en Sardner, 2000).

Segundo, a partir de estas relaciones que se construyen en los intercambios surgen patrones de socialización que no se guían bajo presupuestos comunitaristas sino interculturales, permitiendo que grupos muy distintos convivan en un mismo territorio. Vale la pena resaltar que a pesar de la exigencia del establecimiento de identidades diferenciadas promovidas por la Constitución de 1991, y a pesar de la pervivencia de valores y memorias provenientes de una herencia colonial discriminadora y segregacionista, existen algunas estrategias que históricamente han permitido que grupos distintos se mezclen e interrelacionen entre sí. Por ejemplo, si existe una identidad étnica definida por el reconocimiento otorgado por el Estado, existe otra "identidad cultural que ha permitido el movimiento simbólico de la cultura para ser transmitida a las siguientes generaciones, y que crea categorías como los miti-miti, o los fifty-fifty, los mestizos de los mestizos" (Avella, 2002a: 7), que expresan la manera como la cultura afirma la convivencia y evita el conflicto originado por la afirmación de las diferencias.

Estas estructuraciones sociales comunes en el Caribe surgen también en el Archipiélago, haciendo que las reivindicaciones comunitarias y étnicas que engendran diferencias sean atenuadas por las uniones interétnicas, que si bien no son una solución a la problemática étnica y racial, sí permiten la convivencia entre diferentes grupos (Avella, 2002a: 12). Desde esta perspectiva, la movilidad y la interculturalidad que se desprenden de ella también hacen presencia a manera de un pacto implícito, más que de respeto a la diferencia cultural como un ejemplo de convivencia abierta que caracteriza las identidades de las poblaciones en esta región.

\section{La conformación familiar: del kinship al friendship ${ }^{7}$}

El parentesco y la conformación familiar son rasgos con los que se han caracterizado a las sociedades caribes. Retomar estos elementos desde un marco de análisis alternativo puede ofrecer ciertas pistas a la hora de reflexionar sobre esos otros componentes de los procesos de construcción de identidad. Las sociedades caribes, en su mayoría, han sido caracterizadas como extensas, matrifocales, matricéntricas, donde la mujer domina el hogar y la vida doméstica

\footnotetext{
${ }^{7}$ Del kinship al friendship presenta un juego de palabras. Significa igualar el parentesco a la amistad para demostrar que en el Caribe tanto los lazos de amistad como los lazos consanguíneos son formas de organización social que tienen el mismo valor.
} 
de familia y donde el hombre es relegado a un espacio periférico. Contrariamente para Peter Wilson la vida social del Caribe parece estar fuera del alcance de las estructuras institucionalizadas, por lo que es necesario definir un marco de análisis alternativo a las estructuras familiares institucionales y tomar en cuenta la importancia del agrupamiento informal (Mintz en Wilson, 2003: 30). Para Wilson el parentesco en las sociedades caribes no tiene una función discriminatoria, debido precisamente a valores construidos que definen otro sentido de pertenencia y organización social:

Las clases de parentesco diferentes no están definidas en contraste, ni se enfatizan ciertos principios de conexión genealógica tanto como los asuntos políticos y legales, dando derechos a algunos y a otros no. En vez de eso, el parentesco ejerce una función resumida en el dicho común: we is all one family. Este se invoca a nivel general para enfatizar la igualdad de los miembros de una población y a nivel específico o interpersonal para contra argumentar las afirmaciones de desigualdad (Wilson, 2003: 152).

Si bien el parentesco en sí mismo no es un principio de discriminación, tiene un sentido definido en el que la población puede diferenciarse de acuerdo con su uso en las relaciones sociales. Así, es importante reflexionar sobre la ideología que cimienta el parentesco en el Caribe, ya que el parentesco, primero, se sustenta en una conformación familiar extensa y, segundo, no se limita a las relaciones únicamente consanguíneas, discriminatorias, sino que este se amplia a las relaciones de "padrinazgo" y amistad para cubrir a aquellas personas que están por fuera del núcleo familiar. Por ejemplo, en el Archipiélago de San Andrés, Providencia y Santa Catalina la conformación familiar se estructura de manera extensa y se amplía a partir de las relaciones de amistad. Pero fuera del complejo de relaciones determinadas por consanguinidad y matrimonio existe una marcada tendencia a extender este sistema a uno de carácter clasificatorio:

La gente en general puede ser tratada como aunty, uncle, granma, granpa (...) esto indica que el parentesco puede ser usado como una manera de hacer a los "strangers" amigos. Igualmente el término por el cual la mayoría de los isleños se identifican uno a otro convenientemente es primo. De hecho decir que uno es primo de alguien es lo mismo que decir que uno es pariente o familia (Wilson, 2003: 172).

Este tipo de conformación familiar, no se limita a las relaciones consanguíneas del parentesco, sino que comprende de igual manera las relaciones de solidaridad y reciprocidad establecidas por relaciones de compadrazgo y amistad. Esto demuestra que en el Caribe, y para este caso en el Archipiélago, existe otra forma de comprender y entender la familia, lo cual ha permitido la existencia de una convivencia intercultural donde la amistad actúa algunas veces como principio 
estructural de las relaciones. Oakley Forbes (2002: 25) explica la importancia que cobra el sentido familiar como estrategia de sobrevivencia al flagelo de la trata. Forbes afirma que ante la ruptura de lazos sociales y familiares, o ante situaciones concretas como la ausencia de núcleo familiar o la no oportunidad de crianza de los niños, la solidaridad entre pares se refuerza hasta reinventar los lazos familiares.

Es importante mencionar que el sentido de reciprocidad que estructura la conformación familiar también estructura las relaciones sociales por fuera del dominio doméstico, donde las relaciones de compadrazgo y amistad entre pares tienen mucha importancia ya que su presencia dinamiza diferentes campos de la vida social como el trabajo y la política. Las relaciones de amistad, además de estructurar las relaciones de parentesco, estructuran también la organización social en muchas sociedades del caribe al configurar pequeños grupos informales: "Estos grupos generalmente están conformados por pares, de la misma generación, que comparten la misma situación en la vida y tienen una compatibilidad mutua" (Wilson, 2004: 197). Reflexionar sobre la función social de estos grupos significa pensar ese marco de análisis alternativo a las estructuras familiares e institucionales y tomar en cuenta la importancia del agrupamiento informal que carece de articulación institucional. Para Wilson, estos grupos informales conformados a través de los lazos de amistad y las redes que construyen "son estructuras de divulgación de información y de movilización. Son una expresión en la que se conforma la propia identidad en una cultura común compartida, construyendo un sentido de communitas basado en valores comunes y sentimiento" (Wilson, 2003: 210).

Los valores construidos a partir de la manera como se estructura el parentesco, tanto en la conformación familiar extensa como a partir de relaciones de compadrazgo, o de las relaciones que se tejen entre grupos informales, nos confirman la existencia de los fuertes lazos que han marcado el establecimiento de relaciones interétnicas e interculturales que están siempre presente en el Caribe. Así podríamos entender por qué existe esa diferencia al identificarse y denominarse como raizal, en respuesta a los requerimientos de una identidad de corte étnico propuesta por la Constitución de 1991. Allí son puestos en escena la ancestralidad (africana e inglesa), la particularidad étnica y cultural, que permite el acceso a una serie de derechos que no toda la población de las islas puede poseer, y los discursos ligados a la autonomía y a la libre determinación. Y otra cosa es identificarse como isleño, reconociendo las particularidades que significa haber nacido en el Archipiélago, al compartir una serie de valores tradicionales que se fundamentan en la solidaridad y la reciprocidad, a partir del hecho de compartir una memoria común que, más que buscar la diferencia o 
la segregación, ha promovido la convivencia e inclusión entre distintos grupos, como tradicionalmente ha sucedido en el Caribe.

\section{Algunas consideraciones finales}

A través de estas distintas problemáticas se pone en evidencia lo complejo que resulta aproximarse a los distintos procesos que construyen la identidad y a la manera en que éstos inciden en las dinámicas sociales de una comunidad. Como lo vimos, la identidad isleña raizal, de herencia colonial, se ha construido a través de la relación entre los valores que pretenden reivindicar unas herencias y memorias determinadas y aquellos que tradicionalmente han promovido la inclusión y la existencia de una convivencia intercultural en el Archipiélago. Esta situación, unida a la manera como la Constitución de 1991 ofrece su reconocimiento, nos presenta un panorama mucho más complejo en relación a la dinámica de las identidades de las poblaciones reconocidas, y en particular en el caso de la población isleña-raizal. Esta situación radica en que la Constitución de 1991 está estructurada dentro de la idea "del reconocimiento" de manera unidimensional, "que reduce a comprender el problema desde el ámbito cultural y, por tanto, a intentar dar solución por medio de esta vía: una política cultural de reconocimiento" (Rivera, 2002).

Los valores puestos en escena hoy en día por algunos sectores de la población isleña-raizal son reafirmados para llenar esos contenidos requeridos por una identidad de corte étnico, de acuerdo a los planteamientos exigidos por el Estado colombiano. Aquí están presentes los debates sobre la herencia inglesa y africana para mostrar la particularidad cultural de la población del Archipiélago y legitimar su diferencia, para acceder al reconocimiento de una serie de derechos que no toda la población de las islas puede poseer. En contraposición a este aspecto, encontramos que los otros valores, aquellos que han promovido la convivencia intercultural y se han proyectado desde la manera como se conforma la familia, desde las relaciones de padrinazgo o de las fuertes relaciones de amistad entre pares, valores que no han sido codificados bajo ese lente de lo étnico, paulatinamente se debilitan, tal vez a consecuencia de esta misma situación.

Además de las tensiones producidas por el reconocimiento constitucional y la forma de apropiación del discurso de lo étnico como fundamento de la identidad, existe una diferencia entre estos discursos identitarios creados y proyectados hacia afuera y la manera como la gente nativa del Archipiélago ha construido, reconocido e interiorizado su propia identidad en la cotidianidad. Por eso me parece importante establecer una diferencia entre lo que significa, 
por un lado, identificarse como raizal, como respuesta a los requerimientos de una identidad de corte étnico que utiliza la ancestralidad para reafirmar la particularidad y, por otro lado, identificarse como isleño, reconociendo las particularidades que implica haber nacido en el Archipiélago compartiendo una memoria común y una serie de valores tradicionales, que más que buscar la diferencia o la segregación han promovido la convivencia e inclusión. Esto nos demuestra, una vez más, la existencia de varias contradicciones. En primer lugar, la población isleña-raizal queda en la encrucijada de responder al molde étnico requerido por la Constitución Política de 1991 frente a la naturaleza intercultural, abierta y transfronteriza propia de las identidades de la región caribe. Segundo, se exige construir identidad sobre la base de la segregación y exclusión de otros grupos humanos, chocando contra una de las principales características de la región: la inclusión promovida desde la interculturalidad que históricamente ha impedido la segregación entre la gente del Caribe.

Para entender este proceso de cambio - de la inclusión a la segregación- que hoy comienza a determinar las relaciones sociales entre los diferentes grupos sociales que habitan el Archipiélago, vale la pena señalar que dicho proceso ha ido de la mano con la forma en que se ha establecido la relación entre el Estado colombiano y sectores de la población isleña-raizal. Desde la integración abierta que inicia Colombia sobre las islas a comienzos del siglo XX, son muchos los reclamos y reivindicaciones realizados por sus pobladores al Estado colombiano. Desde entonces los isleños -que no se llamaban raizales en esa época- han manifestado continuamente su descontento ante la manera en que han sido gobernados, planteando la necesidad de equidad y reciprocidad en la relación establecida entre ellos y el gobierno central. En términos generales, podríamos resaltar algunas de las movilizaciones de algunos sectores de la población isleña, como aquellas sucedidas durante la década de 1960 a 1970, que denunciaban el caso del pueblo isleño como víctima del colonialismo y proponían la creación de un Estado autónomo, soberano e independiente. ${ }^{8}$ Otro ejemplo puede ser observado en Sons of the Soil, una de las organizaciones políticas más tradicionales de las islas y que surgió durante la década de 1970. Sons of the Soil fue conocida por sus reivindicaciones en cuanto a la defensa de la identidad isleña en el marco de los problemas ambientales que se desatan con la llegada de migrantes venidos de Colombia continental.

\footnotetext{
${ }^{8}$ En 1965 un memorial firmado por varios isleños fue remitido a la Corona británica solicitando la soberanía de Inglaterra sobre las islas; posteriormente, en 1972, un grupo de isleños residentes en Nueva York, autodenominados Comité Pro-Independencia de San Andrés, elevaron una petición a la comisión de descolonización de las Naciones Unidas para obtener su separación de Colombia bajo la forma de un Estado llamado Federal Republic of Old Providence, por considerar que las islas se encontraban en condiciones de dominación. Este movimiento consiguió hacer llegar a la Organización de Naciones Unidas un documento respaldado por más de diez mil firmas para lograr este propósito.
} 
Posteriormente, gracias a la coyuntura ofrecida por el reconocimiento constitucional de 1991 pero también debido a la crisis económica y el recrudecimiento del conflicto social, surgieron una serie de organizaciones sociales - particularmente de isleños-raizales- que se adjudicaron la lucha por la defensa de la identidad raizal. ${ }^{9}$ Como hemos mencionado, estas organizaciones progresivamente se apropiaron de un discurso étnico y se encargaron de denunciar las situaciones de malestar económico y ambiental que sufren los pobladores. Así, es importante resaltar que a pesar de la existencia de una política estatal de respeto a la diversidad étnica y cultural, en el Archipiélago se continúa denunciando al Estado colombiano como el principal responsable de los conflictos y de los efectos que estos han tenido en detrimento de la identidad de la población isleña-raizal. ¿Ha sido entonces efectivo el reconocimiento constitucional de 1991 para paliar muchos de los conflictos que actualmente se viven en el Archipiélago, o por el contrario esta situación los ha recrudecido?

Si la identidad isleña-raizal en un inicio se configuraba en respuesta a las imposiciones realizadas por el Estado colombiano y fue sustentada en ideas de reciprocidad e igualdad, hoy su transformación se presenta como problemática, y más que ofrecer soluciones reales a los múltiples problemas que se presentan en el Archipiélago, los ha agudizado. Es importante señalar que a pesar de los grandes alcances de la Constitución de 1991 en cuanto al reconocimiento de derechos étnicos y colectivos, ésta también ha generado nuevos conflictos sociales, que en el caso que nos ocupa se materializan en una gran tensión entre isleños-raizales y pañas-continentales y en el recrudecimiento de la confrontación con el Estado colombiano. Vale la pena mencionar que la ruptura de esta convivencia intercultural no es sólo culpa de la manera como han actuado ciertos sectores de la población raizal en respuesta al modelo de reconocimiento de la Constitución Política de 1991. Este es un punto muy importante a tratar y que ha sido dejado de lado en lo que concierne al reconocimiento de derechos de ciertas minorías, la cuales han sido obligadas a crear y recrear una identidad en contextos sociales y económicos bastante difíciles. Por eso hoy en día en el Archipiélago, dadas las problemáticas de la población isleña-raizal, los procesos de construcción de identidad no pueden ser analizados sin contemplar las alteraciones acarreadas por la llegada de miles de personas foráneas a las islas, los cambios en su territorio y los intercambios que se han dado como fruto de este encuentro. Pero, sobretodo, no pueden ser analizados sin abordar la problemática relacionada con la inequitativa distribución de recursos que hoy existe en las

\footnotetext{
${ }^{9}$ De esta manera, un grupo de isleños sanandresanos liderado por pastores bautistas, retomando algunas de las ideas establecidas por Sons of the Soil, decide crear el denominado Movimiento Raizal, más conocido hoy como AMEN-SD: Archipielago Movement for Self Determination.
} 
islas, que no sólo compete a la población raizal, sino también a esa población continental que está en el ojo del huracán y a ese élite -tanto nacional como extranjera- que monopoliza los recursos y permanece al margen del conflicto. Es a esta diferenciación económica real y concreta que se opone el principio que caracteriza a los valores tradicionales de la población isleña: la creación de un igualitarismo simbólico que, independientemente de las diferencias sociales y económicas, preserva a la igualdad como el elemento que asegura la cohesión social y permite la convivencia dentro de la diferencia.

Hoy en día, como hemos visto, comienza a existir un ambiente más conflictivo en las islas. Un ambiente marcado por el recrudecimiento de las diferencias, que ha surgido y, digámoslo con franqueza, se ha fortalecido a partir del mismo reconocimiento constitucional de 1991. Ambiente que por lo demás tiene influencia sobre la construcción de identidades, las confrontaciones a las que se ven sometidas las minorías étnicas, la manera en que se relacionan con otros grupos y las dinámicas que demarcan sus procesos de inserción en la sociedad nacional. Las problemáticas relacionadas con la identidad y la etnicidad son elementos que nos conllevan a reflexionar sobre cómo se configuran los procesos de construcción de nación, los cuales oscilan hoy en una dicotomía: actuar en razón tanto del reconocimiento y la autonomía como del fortalecimiento de un proyecto de Estado-nación.

\section{Bibliografía}

- Agudelo, Carlos, 2004, Politique et Populations Noires en Colombie, Paris: L'Harmattan.

- Avella, Francisco, 2002a, "La diáspora creole anglófona del Caribe Occidental”, en: Revista Jangwa Pana, número 2, Universidad de Magdalena.

2002b, "Conflictualidad latente y convivencia abierta: El caso de San Andrés", en: La niversidad piensa la paæ: obstáculos y posibilidades, Bogotá: Universidad Nacional de Colombia.

2000, "Proceso identitario y pensamiento caribe", Material inédito de la Maestría en: Estudios Caribeños. Instituto de Estudios Caribeños- Universidad Nacional de Colombia, sede San Andrés Isla.

- Barth, Frederick, 1976 (1969), Los grupos étnicos y sus fronteras: La organización social de las diferencias culturales, México, Fondo de Cultura Económica.

- Bolivar, Ingrid, 1998, “Ciudadanía multicultural y construcción de un espacio 
público: El caso del Chocó y la ley 70 de 1993”, en: Formación de investigadores: estudios sociales y propuestas de futuro, Bogotá: Tercer Mundo-Colciencias.

- Constitución Política de Colombia, 1991.

- Cunin, Elisabeth, 2000, 'Relations Interethniques et Processus D'identification Carthagène”, en: Cahiers des Amériques Latines, No. 33, págs. 127-153.

- Chivallon, C., 2004, La Diaspora Noire des Ameriques: Experiences et Théories, Paris: Editions CNRS.

- Forbes, O., 2002, "Creole Culture \& Language in the Colombian Caribbean", en: Cuadernos del Caribe, No. 3, San Andrés Isla: Instituto de Estudios Caribeños, Universidad Nacional de Colombia.

- Giraldo J. M., 1987. "El grito de una etnia despojada. Movimiento Sons of the Soil (SOS). Hijos raizales, San Andres y Providencia”, en: Revista Controversia, Cinep.

- Gros, Christian, 2000. Politicas de la Etnicidad: Identidad, Estado y Modernidad. Bogotá. Instituto Colombiano de Antropología.

- Hoffman, O. et al., 2002, Afrodescendientes de las Américas, Universidad Nacional de Colombia - Instituto Colombiano de Antropología, Ed. Unibiblos, Bogotá.

- Losonczy, A. M., 2006, La trama interétnica: ritual, sociedad y figuras de intercambio entre los grupos negros y emberá del chocó. Ed. ICANH-IFEA. Bogotá.

2002. "De cimarrones a colonos y contrabandistas: figuras de movilidad transfonteriza en la zona dibullera del Caribe colombiano", en: Hoffman, O. et alii, Afrodescendientes de las Américas, Universidad Nacional de Colombia - Instituto Colombiano de Antropología, Ed. Unibiblos. Bogotá.

- Morales, Patrick, 2000, "El Corpus Christi en Atánquez: identidades diversas en un contexto de reetnización”, en: Revista Colombiana de Antropología, Vol. 36, Eitorial ICANH, Bogotá.

- Parsons, James J., 1985, San Andrés y Providencia: Una geografía histórica de las islas colombianas del Caribe. Bogotá, El Ancora Editores.

- Poutignat, P. et Streiff-Fenart J., 1999, Théories de l'ethnicité, Paris, Presses Universitaires de France.

- Price, T. J., 1954, "Algunos aspectos de estabilidad y desorganización en una comunidad isleña del Caribe colombiano", en: Revista Colombiana de Antropología, Vol. III, pags. $12-54$, Bogotá. 
- Ramírez, S. y L. A. Restrepo, 2001, "Visiones y proyectos para el Archipiélago de San Andrés, Providencia y Santa Catalina”, Cuadernos del Caribe, No. 2, IEPRI - Instituto de Estudios Caribeños. Universidad Nacional de Colombia.

- Ratter, B., 2001, Redes Caribes, San Andrés y Providencia y las Islas Cayman: entre la integración económica mundialy la autonomía cultural regional. Bogotá, Universidad Nacional de Colombia.

- Rivera, M. C., 2002, Old Providence: minoría no armonía. De la exclusión a la etnicidad. Tesis de pregrado. Departamento de antropología. Universidad de los Andes.

- Restrepo, E., 2006, "Identidades: planteamientos teóricos y sugerencias metodológicas para su estudio", en: Revista Jangwa Pana, número 5, Departamento de Antropología, Universidad del Magdalena. 2005. Politicas de la teoría y dilemas en los estudios de las Colombias negras. Editorial Universidad del Cauca. Colección política de la alteridad.

- Sandner, Gerard, 2000, "La Cuenca del Caribe: Concepto e Implicaciones de "Unitas Multiplex"”, Material Inédito, Maestría de Estudios Caribeños. Universidad Nacional de Colombia. Sede Caribe.

- Serbín, A., 1987, Etnicidad, clase nación en la cultura política del Caribe de babla inglesa, Caracas, Biblioteca de la Academia Nacional de Historia.

- Vollmer, L., 1997, Historia del poblamiento del Archipiélago de San Andrés Providencia y Santa Catalina, San Andrés Isla. Ediciones Archipiélago, Fondo de Cultura, 1997.

- Valencia, I. H., 2002, Elmovimiento raizal: Una aproximación a la identidad raizal a través de sus expresiones político-organizativas, Monografía de grado, Universidad Nacional de Colombia, Facultad de Ciencias Humanas, Departamento de Antropología.

- Wilson, Peter J., 2003 [1973], Las travesuras del cangrejo. Un estudio de caso Caribe del conflicto entre reputación y respetabilidad, Universidad Nacional de Colombia, Editorial Unibiblos. 
